\title{
Coronavirus Disease (Covid-19): Reviews, Applications, and Current Status
}

This paper was downloaded from TechRxiv (https://www.techrxiv.org).

\section{LICENSE}

CC BY-SA 4.0

SUBMISSION DATE / POSTED DATE

$26-07-2020$ / 31-07-2020

CITATION

Alam, Tanweer (2020): Coronavirus Disease (Covid-19): Reviews, Applications, and Current Status. TechRxiv. Preprint. https://doi.org/10.36227/techrxiv.12720404.v1

$\mathrm{DOI}$

10.36227/techrxiv.12720404.v1 


\title{
Coronavirus Disease (Covid-19): Reviews, Applications, and Current Status
}

\author{
Tanweer Alam \\ Faculty of Computer and Information Systems \\ Islamic University of Madinah, Saudi Arabia \\ Email: tanweer03@iu.edu.sa
}

\begin{abstract}
Currently, the COVID-19 has directly affected the millions of humans lives. The symptoms of the disease involving fever, malaise, chest infection, and breathing difficulties, were identified, and its existence is continuously becoming restructured. The World Health Organization (WHO) had mentioned the wide diagnostics test besides COVID-19 that would also assist medical facilities to recognize infectious diseases as well as currently focusing efficiently on preventing and afterward defeating this viral disease. The infection is usually transmitted among human beings in direct contact, greatest through the liquid bubbles generated through cough, sneeze, or speaking. This paper reviews the COVID 19 pandemic, its history, current updates, contact tracing applications, and use of emerging technologies like the Internet of Things (IoT) and Blockchain for stopping the spreading and provide service online to the patient from a distance.
\end{abstract}

Keywords: COVID 19, IoT, Blockchain, Infection, Emerging Technologies, mHealth.

\section{Introduction}

Various infectious diseases had already arisen in lots of places in recent years, like viruses such as swine flu, chickenpox, and Nipah virus, etc. Now, a newly formed viral infection has appeared in Wuhan Region, a Chinese city, and the original genetic testing results for such a virus don't always fit the previously analyzed viruses, indicating COVID 19 [1]. From the starting of 2020, COVID-19 has had a significant impact on human health [2]. Because of the effects of COVID-19 and the global recession caused by a lockdown in various nations. Once people accept social distances and depend mostly on new technologies, this is evidenced that IoT security issues are increasing and there are more illegal activities [3]. Its requirement for IoT security services is expected to rise as a result of the COVID-19 disease outbreak and improve the economy for IoT security issues [4].

COVID-19 disease is a big issue for healthcare systems worldwide [5]. The world's current epidemic of coronavirus infection due to extreme pneumonia symptoms COVID-19 epidemic, often recognized as the coronavirus epidemic [6]. This disease was firstly found in Dec 2019 in Wuhan city of China [7]. It is the biggest town in Central China with the populace of more than 11 million persons. On 23rd Jan 2020, Wuhan has shut down its transportation [8]. Also, nearby cities like Huangang, Ezhou have shut their shopping centers. It indicates that more than 18 million people have been placed in isolation. WHO praises Chinese for its remarkable dedication to self-isolation and reducing transmission of the virus. China replied appropriately by alerting the WHO for infection and updating sequencing data more with the global system upon that discovering the cause of disease. WHO reacted quickly by organizing the production of diagnostic testing; making recommendations on healthcare services, sample selection, and medication; and transfer updated data on the disease [9]. Many nations in the world, and the USA, were examining Wuhan visitors for infection, intending to identify COVID-19 cases before the virus infects more.

This disease was announced on Jan 30, 2020, a global health Crisis of Worldwide Significance [10]. Since about 15 July 2020, upwards of 13.3 million patients of COVID-19 are being confirmed in more than 190 nations across the globe, 585,000+ casualties and 7.5+ million have been recovered [11]. COVID-19 influences many individuals in several situations. Many affected individuals develop mild to severe infectious diseases as well as recover without hospital treatment.

\section{History and Timelines}

1.12.2019: First COVID 19 patient identified in Wuhan, China, healthcare center. This infected person being originally recognized as having an infection from a bat in the Huanan fish market. The theory 
which is currently under debate as experts claim possible sources, such as that insufficient security policy at the Wuhan Institute of Virology contributed towards its escaping.

31.12.2019: The Wuhan administration alerted people about the warning symptoms of an epidemic of pneumonia disease. This announcement conveyed the appearance of awareness, summarizing directives to city health centers; outlining active patient and health inquiries and seeking medical attention for severe cough as displaying signs of infection; and urging the people to use face masks and minimize their daily routine to visit populated places. Twenty-seven cases were active, seven cases were in severe condition and two were recovered. However, there were neither any casualties found and nor any healthcare professional infected, no signs of transmitting the disease to person-to-person, start causing pneumonia infectious disease under the investigative process.

7.1.2020: Researchers in China have declared a newly discovered virus named coronavirus.

10.1.2020: WHO has provided a detailed collection of online clinical advice to every nation on how to identify, monitor, and treat suspected cases, depending upon what is understood as to the disease at the present. Such advice also discussed with WHO Provincial Officers for urgent situation Responsibilities to be communicated with WHO members in nations.

11.1.2020: First death was confirmed in Wuhan due to coronavirus.

21.1.2020: USA was declared its first active case of COVID 19.

23.1.2020: China authority shutdown the Wuhan city.

24.1.2020: France and the UK were declared the first COVID 19 case.

30.1 2020: The WHO has called the virus an international health crisis while $9,000+$ patients have been identified globally, eighteen nations and territories.

India was declared the first COVID 19 case.

1.2.2020: Spain was declared the first COVID 19 case.

2.2.2020: First death was confirmed outside china due to coronavirus.

7.2.2020: First death of Chinese doctor Dr. Li Wenliang was confirmed due to coronavirus.

16.2.2020 to 24.2.2020: WHO-China Joint Commission, encompassing specialists across the USA, Canada, Japan, Germany, South Korea, Russia, and Singapore spent significant time in China and traveled to Wuhan. These scientists talked to government authorities, researchers, and healthcare professionals in healthcare services.

28.2.2020: New Zeeland was declared the first COVID 19 case.

29.2.2020: First death in the USA was confirmed due to coronavirus.

11.3.2020: WHO has reported the coronavirus epidemic that could be described as a disease outbreak. It was identified as the rapid emergence of a viral disease for humans whose weak immune system.

18.3.2020: WHO and collaborators were launching the Solidarity Project, a multinational research study that seeks to produce strong evidence from all over the globe to identify very successful solutions for COVID-19 pandemic.

19.3.2020: China announced that there were not any newly reported COVID 19 cases.

1.4.2020: Six weeks old infant was dead from coronavirus, which was believed to be among the newest baby deaths from the COVID 19 disease outbreak.

11.4.2020: COVID-19 deaths in the US have reached the 20,000 milestones, including over half a million reported cases nationally.

20.4.2020: Petroleum prices in the USA dropped below historically low levels in negative because the global market collapsed.

7.5.2020: WHO warns that the COVID-19 can kill around 83,000 to 190,000 in African countries in 2020 , if not controlled.

2.6.2020: Wuhan reported no new case for the first time.

9.6.2020: New Zealand announced their country as COVID-19 free country.

10.6.2020: Recorded 2 million COVID 19 cases reached in the USA.

3.7.2020: COVID 19 cases reached eleven million worldwide.

16.7.2020: COVID 19 cases reached 13,731,030 active cases, 587,779 deaths and 8,181,025 recovers worldwide.

\section{Spreading the Infection}

The COVID-19 poses the immense worldwide issue which had needed unparalleled rates to action. Throughout one way, there is a major crisis: COVID-19 has arisen as a new disease against which 
people have no immunity, travels extraordinarily rapidly, has a higher death rate, and therefore can overpower the performance of health facilities against handle a very critically infected. However, this is not unmatched: parallels with so many other viral diseases with current pandemics indicate the infection prevention mechanisms are well known and current techniques could be used to promote the production of new vaccinations and medications [12].

The main objective is to reduce the death rate of people with extreme COVID-19 disease. Throughout the lack of adequate antiviral drugs, vigorous restoration of functional status seems to be the treatment option. The medication strategy to enhance cure rates can be more improved in the upcoming as well as the vaccination will be successfully designed for COVID-19 disease.

\section{Treatments}

Until there are no vaccinations or unique antivirals of COVID-19 disease. Disease control depends on the provision of conditions, caring, loneliness, including progressive results [13]. On 11 March 2020 WHO declared the outbreak of COVID-19 a health crisis of worldwide importance. The spreading of the infection has happened in several nations worldwide.

\section{Emerging Technologies used for COVID-19 outbreak}

A large amount of money and other resources are being used to tackle the continuing COVID-19 infection. New techniques such as AI, Blockchain, IoT, etc. are now using to fight with COVID 19 virus [14].

\subsection{Blockchain Technology}

Blockchains technologies could be used to measure the allocation of infection information, charities, recovery delivery as well as other responding rapidly and effectively without violating confidential information [15]. Blockchains could provide reliable, transparent, and secure health information. Many organizations were suspected of misrepresenting the facts throughout that disease outbreak, and blockchains would help to overcome it by offering open and secure health information [16].

The blockchain-based disease outbreak network could be used to monitor the transmission of the infection, the number of individuals affected, and the number of individuals recovered from COVID19. Blockchains offers a procedure to make a significant contribution, construct, and monitor the workflow of COVID-19 treatment. However, when the epidemic ends, people could search at how blockchain assisted everyone to get into it, and crazies would be persuaded to adopt the technology for daily needs.

A distributed architecture, timing and dynamically detecting characteristics of Blockchains [17] making it a good option for electronic accessing all reported incidents of COVID-19 depending on the related infectious disease sequence with each reported incident. Storing a new confirmed case ensures that a new associated infection pattern is created and processed, besides, all contact persons and risky places accessed by the confirmed case of COVID-19 are also processed as infection cases in the blockchain.

\subsection{Internet of Things}

IoT is a collection of interrelated smart objects/activities which complies across all networking devices like; equipment, software, network connectivity, and any other digital/smart phone requirements which eventually make it sensitive by monitoring network enhancement and gathering. When humans think a bit more about IoT, it goes beside a definition that creates a technical infrastructure context that effectively allows for the incorporation and efficient processing of information between the individual need and the network operators [18], [19].

IoT provides important advantages in health services and is becoming a key technological global leader [20]. Including the growing range of infectious diseases, IoT has often found its way into the healthcare organizations, from a variety of applications, like telehealth, digital scanning, hospital admissions reporting, drug control, smart security, digital staff, smart ambulances, and many more. For current situations of COVID-19 have inspired physicians of IoT-based telemedicine to continue providing methods rapidly to fulfill the needs of the infected people [21].

\section{3 mHealth}


The Stanford Medicine work indicates that health information gathered from wearable devices could help to identify viral infections days before symptoms develop [22]. The researchers there started up the COVID-19 wearable devices investigation, that focuses on determining information obtained from wearable devices, such as blood pressure, fever, and heart rate could be used to identify an infected person such as COVID-19 [23].

\section{Contact Tracing Apps}

Contact tracing apps are mobile applications that use Digital Communication Surveillance to react to the coronavirus outbreak, such as identifying individuals who may be in contact with an infected individual. Numerous mobile apps are being built in some regions via authorized government support. Several other methods are suggested for the production of contact detection and tracking. Such as the epidemic of COVID-19 virus, medical researchers are now running around to develop touch monitoring systems, software, and apps to identify and notify everybody who contacts to infected individuals.

\subsection{Aarogya Setu}

This app tracks location data that needs a regular connection to a smartphone that is intrusive from a privacy-related point of view. It can be done, and to promote quality assurance regulations, and so on. [24]

\subsection{Kwarantanna domowa}

Through fact to several other problems, this app gives the chance to investigate national healthcare insurance institutions that can provide medication as well as souvenirs in sensible scenarios. Individuals can also quickly inform a member of the team. Users also have easy access to the right information useful throughout quarantine and service is provided contact tool beyond citizens. Developers have improved it with a self-monitoring system for treatment a few days prior. The program has been formally established by Poland's nation [25].

\subsection{Tawakkalna (Covid-19 KSA)}

The goal of this application is to monitor the movements of people across Saudi Arabia. It contains approval to leave or every person's health issues. It is a simulation for the Chinese research study. This is a color-based coder system that represents the situation of the person. One greenish light means that it is clean and allowed to drive. A yellowish color reflects the suspect and is not allowed to move. Red means both impaired and excluded from moving. This is experiencing and in the trial version to check the efficacy of such a device. Another way to meet the group is to send SMS to all arbitrarily to send everybody the facilities they need. The health ministry of Saudi is promoting and funding this application. [26].

\subsection{TraceTogether}

This is created to allow community-driven touch-tracking to support forward-going national recommendations to tackle the COVID-19 epidemic. The Singapore government introduced this app, which utilizes the customizable Blue-Trace specification to allow wifi access tracking [27]. This was designed and created by community information systems on 20 March 2020. Because since the release of the apps, 17 percent of the total population has been installed, which means more than 2,100,000 people.

\subsection{LetsBeatCOVID}

This is designed to provide persons with a short discussion on health, especially COVID-19 risk, in attempts to save even more person's lives[28]. It was released by MedShr, a health app used by more than a million practitioners. People are asked to review a brief online survey about themselves, but they are also asked to link in the information of their families. 


\subsection{CovidWatch}

This app was developed via a joint venture with Stanford University, the true dedication of people to support themselves and their communities whilst still surrendering privacy. It uses Bluetooth signals to identify people when they are near to each other, or secretively informs people while they're in contact with infected persons. This distinguishing feature of this app is that any party, including the authority, could not track who has been informed. To confidential data-preserving, cooperative wireless reach monitoring, it was among the first apps to release an open data configuration [29].

\section{Current situation}

According to the Worldometer, the total Coronavirus cases are 3,952,406, total deaths are 592,757 and total recovery is $8,284,285$ as of 17 th July 2020 at 08.35 AM [11]. Figure 1 shows the active, closed, daily wise new cases and deaths according to the worldometer [11]. Figure 2 shows the number of cases in India due to COVID 19 [11]. Figure 3 shows the daily deaths in India due to COVID 19 pandemic [11].

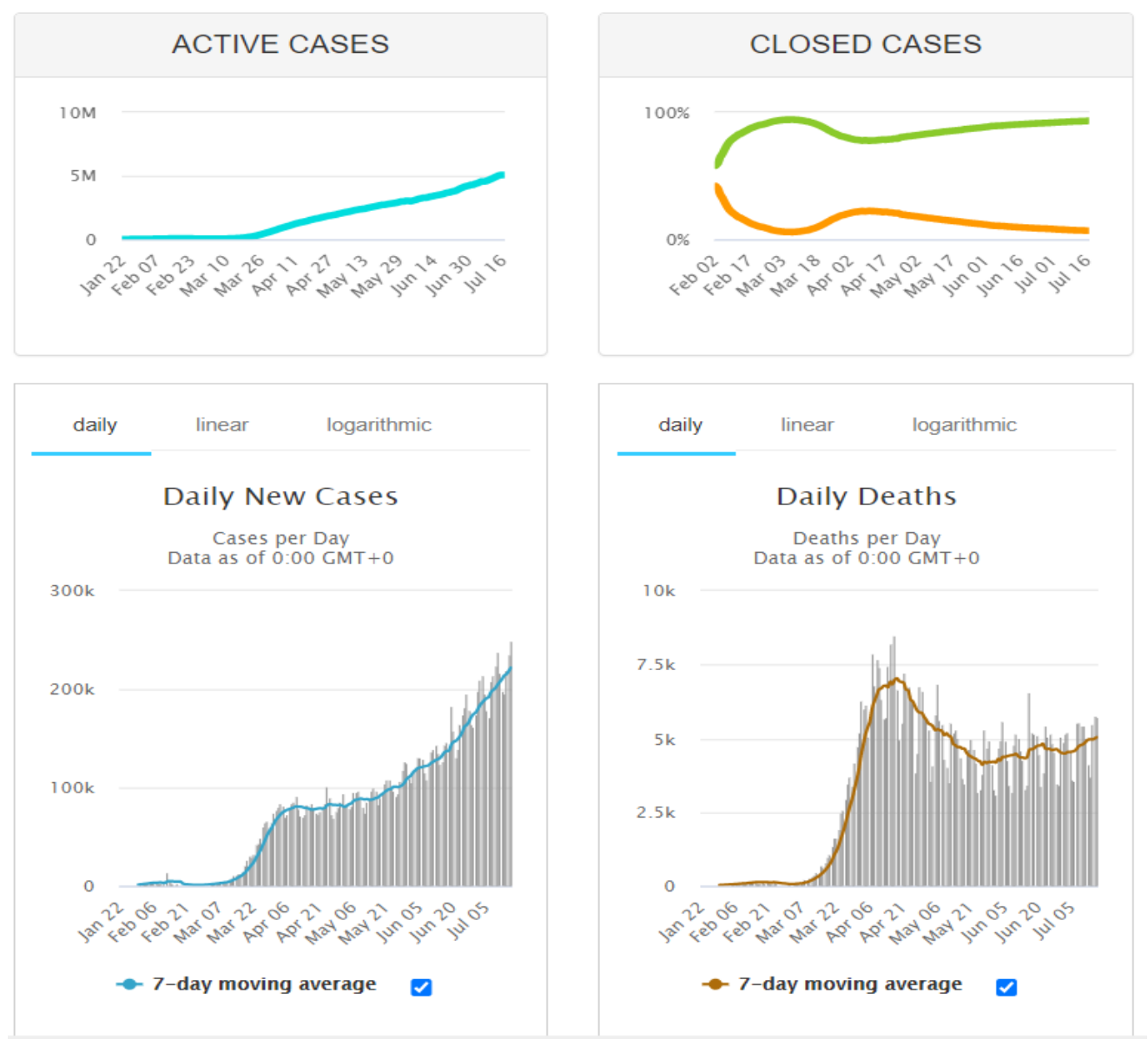

Figure 1: Current world situation of COVID 19 cases 


\section{Daily New Cases}

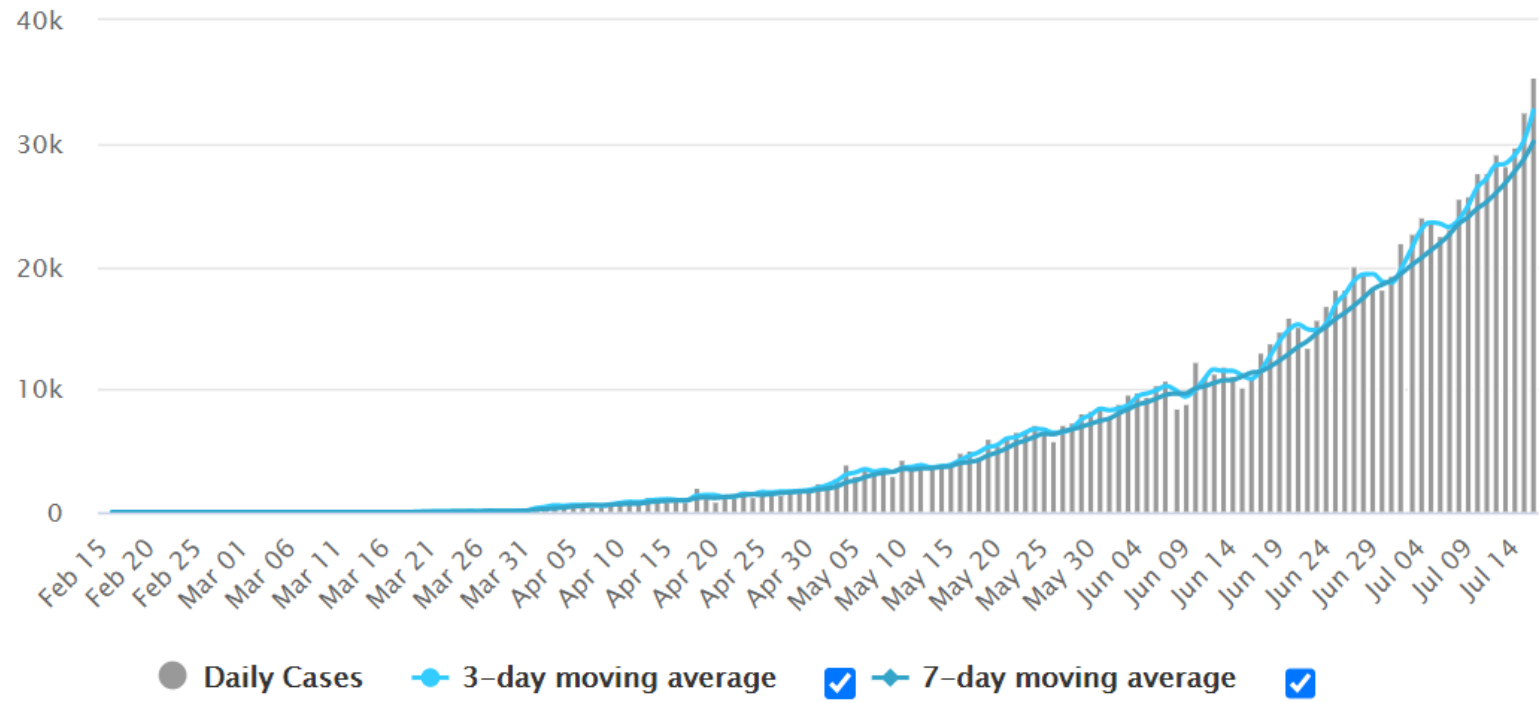

Figure 2: Number of cases in India due to COVID 19 Daily Deaths

Deaths per Day Data as of 0:00 GMT+8

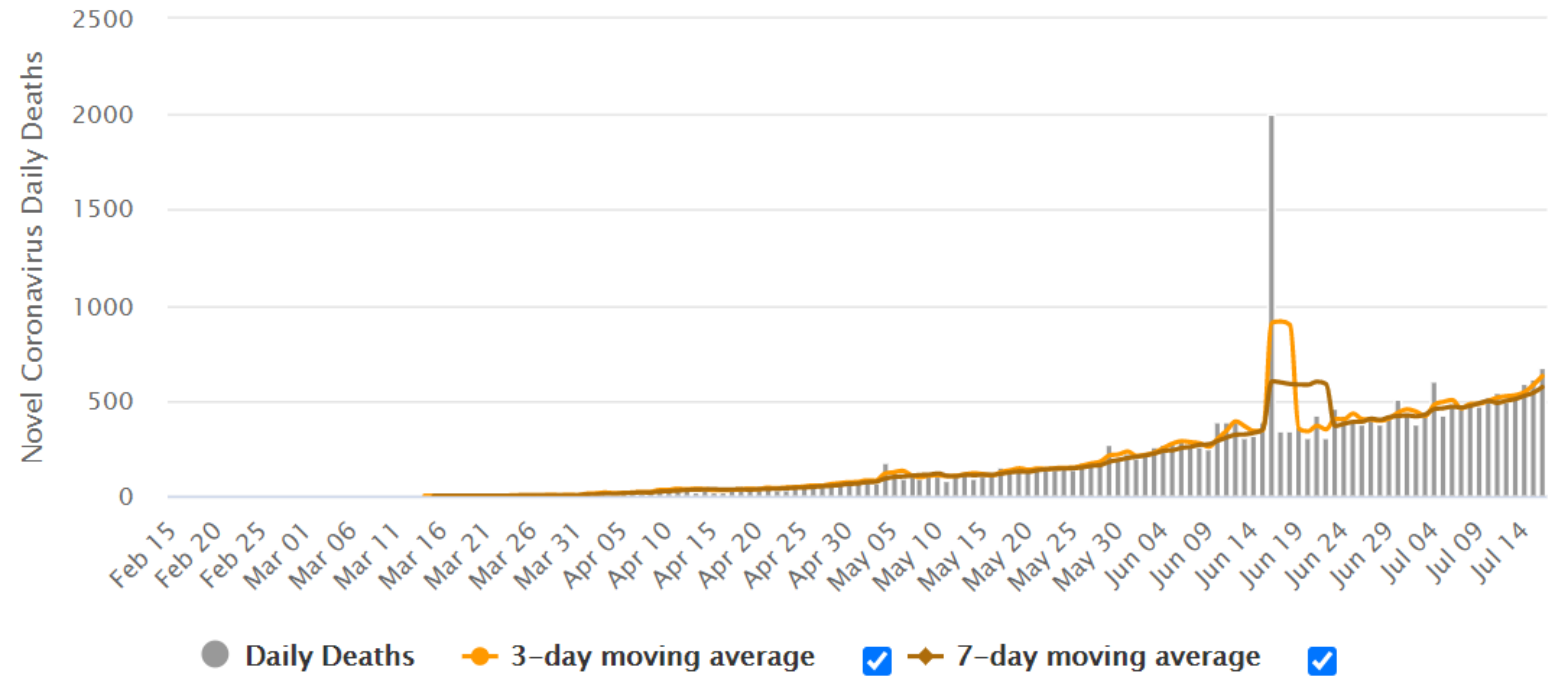

\section{Conclusion}

Figure 3: Daily deaths in India due to COVID 19

COVID-19 is mainly spread by an infected person or by touch to polluted objects. The contact may happen generally in the working environment, including working place, transportation, or on the route of the working environment. Coronavirus is the relatives with dozens of viral infections. Many of these infectious agents are bat, chicken, camel, and cat, etc. Infrequently, diseases that affect an animal may transform to other animals.

\section{References}

[1] Dhama, K., Sharun, K., Tiwari, R., Sircar, S., Bhat, S., Malik, Y. S., ... \& Rodriguez-Morales, A. J. (2020). Coronavirus disease 2019-COVID-19. 
[2] Mehta, P., McAuley, D. F., Brown, M., Sanchez, E., Tattersall, R. S., Manson, J. J., \& HLH Across Speciality Collaboration. (2020). COVID-19: consider cytokine storm syndromes and immunosuppression. Lancet (London, England), 395(10229), 1033.

[3] Shin, D. H., \& Park, Y. J. (2017). Understanding the Internet of Things ecosystem: multi-level analysis of users, society, and ecology. Digital Policy, Regulation and Governance.

[4] Singh, Ravi Pratap, Mohd Javaid, Abid Haleem, and Rajiv Suman. "Internet of things (IoT) applications to fight against COVID-19 pandemic." Diabetes \& Metabolic Syndrome: Clinical Research \& Reviews (2020).

[5] Tanne, J. H., Hayasaki, E., Zastrow, M., Pulla, P., Smith, P., \& Rada, A. G. (2020). Covid-19: how doctors and healthcare systems are tackling coronavirus worldwide. Bmj, 368 .

[6] Singhal, T. (2020). A review of coronavirus disease-2019 (COVID-19). The Indian Journal of Pediatrics, 1-6.

[7] Guan, Wei-jie, Zheng-yi Ni, Yu Hu, Wen-hua Liang, Chun-quan Ou, Jian-xing He, Lei Liu et al. "Clinical characteristics of coronavirus disease 2019 in China." New England journal of medicine 382, no. 18 (2020): 1708-1720.

[8] Sohrabi, C., Alsafi, Z., O’Neill, N., Khan, M., Kerwan, A., Al-Jabir, A., ... \& Agha, R. (2020). World Health Organization declares global emergency: A review of the 2019 novel coronavirus (COVID-19). International Journal of Surgery.

[9] Lewnard, J. A., \& Lo, N. C. (2020). Scientific and ethical basis for social-distancing interventions against COVID-19. The Lancet. Infectious diseases, 20(6), 631.

[10] Velavan, T. P., \& Meyer, C. G. (2020). The COVID-19 epidemic. Tropical medicine \& international health, 25(3), 278.

[11] WorldoMeter,

https://www.worldometers.info/coronavirus/?utm_campaign=homeAdvegas1?\#countries

[12] Kahn, J. S., \& McIntosh, K. (2005). History and recent advances in coronavirus discovery. The Pediatric infectious disease journal, 24(11), S223-S227.

[13] Anderson, R. M., Heesterbeek, H., Klinkenberg, D., \& Hollingsworth, T. D. (2020). How will country-based mitigation measures influence the course of the COVID-19 epidemic?. The Lancet, 395(10228), 931-934.

[14] Lixing, Z. (2020). Impact of the COVID-19 Outbreak on the World and the Inspirations. Global Journal of Management And Business Research.

[15] Tanweer Alam, "IoT-Fog: A Communication Framework using Blockchain in the Internet of Things", International Journal of Recent Technology and Engineering (IJRTE), Volume-7, Issue-6, 2019.

[16] Tanweer Alam, Mohamed Benaida, "Blockchain, Fog and IoT Integrated Framework: Review, Architecture and Evaluation", Technology Reports of Kansai University, Volume - 62, Issue 02, 2020. [17] Alam, Tanweer. (2018) "A reliable framework for communication in internet of smart devices using IEEE 802.15.4." ARPN Journal of Engineering and Applied Sciences 13(10), 3378-3387.

[18] Alam, Tanweer, and Mohammed Aljohani. "Design and implementation of an Ad Hoc Network among Android smart devices." In Green Computing and Internet of Things (ICGCIoT), 2015 International Conference on, pp. 1322-1327. IEEE, 2015. DOI: https://doi.org/10.1109/ICGCIoT.2015.7380671

[19] Alam, Tanweer, and Mohammed Aljohani. "An approach to secure communication in mobile ad-hoc networks of Android devices." In 2015 International Conference on Intelligent Informatics and Biomedical Sciences (ICIIBMS), pp. 371-375. IEEE, $2015 . \quad$ DOI: https://doi.org/10.1109/iciibms.2015.7439466

[20] Aljohani, Mohammed, and Tanweer Alam. "An algorithm for accessing traffic database using wireless technologies." In Computational Intelligence and Computing Research (ICCIC), 2015 IEEE International Conference on, pp. 1-4. IEEE, 2015. DOI: https://doi.org/10.1109/iccic.2015.7435818

[21] Alam, Tanweer, and Mohammed Aljohani. "Design a new middleware for communication in ad hoc network of android smart devices." In Proceedings of the Second International Conference on Information and Communication Technology for Competitive Strategies, p. 38. ACM, 2016. DOI: https://doi.org/10.1145/2905055.2905244

[22] Alam, Tanweer. "mHealth Communication Framework using blockchain and IoT Technologies." International Journal of Scientific \& Technology Research 9, no. 6 (2020). 
[23] Fight COVID-19 through the Power of People, Healthcare Innovation Lab at Stanford University, Link: https://innovations.stanford.edu/wearables

[24] App, Aarogya Setu Mobile. "MyGov. in.(2020)."

[25] Długosz, Piotr. "Raport z badań:,Krakowscy studenci w sytuacji zagrożenia pandemią koronawirusa"." (2020).

[26] Perveen, Shagufta, Raha Orfali, Shafiq Azam, Hanan Y. Aati, Khulud Bukhari, Sara I. Bukhari, and Areej Al-Taweel. "Coronavirus nCOVID-19: A Pandemic Disease and the Saudi precautions." Saudi Pharmaceutical Journal (2020).

[27] TraceTogether, Team. "How does TraceTogether work?."

[28] Rosenkrantz, Leah, Nadine Schuurman, Nathaniel Bell, and Ofer Amram. "The need for GIScience in mapping COVID-19." Health \& Place (2020): 102389.

[29] Watch, Covid. "Covid Watch." last access 7 (2020). 